\title{
Education... destination... new directions
}

\begin{abstract}
The following article discusses the role of Venezuela's current education and Its Institutions. It proposes a way to make and build the educational process, respect, solidarity and quality of life. Through the dialectical method the author takes us into new directions to be taken by educational process.
\end{abstract}

Keywords: contextualized, social justice, utopia
Volume 2 Issue 6 - 2018

\author{
Yeslando J Gonzalez B \\ Department of Education, University of Pedagogical,Venezuela \\ Correspondence: Yeslando J Gonzalez B, Department of \\ Education, University of Pedagogical, UPEL, Venezuela, Tel 0424- \\ 7644407,Email yeslandogonzalez778@hotmail.com
}

Received: October 24, 2018 | Published: December 20, 2018

\section{Introduction}

Societies fighting for their development depend on their education to highlight the personalities of its citizens. So the idea of universal man, the citizen, the professional tends to perfection because it will depend on the proper functioning of the institutions as mentioned Prieto Figueroa (1997). Generally speaking, goals and objectives, had, have and will have scope for the proper functioning of societies, educational institutions (public or private). They are aspirations of communities that go beyond or overlap the individuality of the subject, which is beyond him. These aspirations, achievements, progress and visions of communities are achieved only through education. And the purpose for which an individual is educated is an aspiration of each member within a society. It is forming his personality, fair, conscientious but not permeable to the vices of society being.

\section{Materials and methods}

Moreover, personality and purpose of education must be added to the community because in the latter is integrated as a whole, and mentioned that the objective of the same, from the point of view of the individual, is the autonomous personality, contextualized in daily life, for participation in the historical collective life, which means that the concept of education generally in almost every country in the world is linked the formation of man. Of course, this concept stems from the need for companies to transmit their cultural, historical, and ancestral and disseminate a whole body of knowledge, habits, ideas and qualities to future generation's treasure that will distinguish and unite in their differences.

Similarly, education being the connecting thread with future generations, it allows individuals to rise within societies and perceived as a trainer work of the capabilities of the notions for social development; excessive regulatory nature should correspond to the realities surrounding the human, as utopian and achievable being, like technology, cyberspace, social networks, electronic espionage turned into tangible reality that young people today, they live and face whereas adults, perplexed, hesitant we fail to understand the times in inventing concepts and educational strategies to try to restructure its reality and overlap the already weakened existence. Not for lack of knowledge but to try to understand the way of life that he created, community, politicians, the idea of creating a new educational system, "the unwise consultations", the linguistic vacuum university transformation to transform the empty promise and not fulfill fill future of suspicion generations and become the price that has to pay the history of humanity, which have been very few "players" in the role of the other. The old speeches; democratic-demagogic, hallucinatory arise from realities. So if we do not change and continue doing things the same way, we live wrong and we will pay the consequences. It is clear that education is the right medium for the formation of personality and identity of human beings but this must be based on truth and not the hologram invented a happiness that does not exist, which is vague and imprecise. You cannot keep pointing out, in favor of groups of power, capitalism or communism that end up being accused: if they exist, "spirits" in terms of superstition. Under such conditions, true education of man to man and acquires a relevant role in society. It is still possible to form institutionally individuals that meet the needs of political and social productive socio-economic system, systems development but also have to change. Only the man and his education, respect for others and their dignity, and love of nature are responsible for a better world.

In this vein, the diversity of philosophical positions and the plurality of ideologies that exist in the world, are important factors for a real discussion on the academic side and to rethink the future of our children. They are the prelude to a definition of modern life, placing at risk the academic and work continuity, at the time that educational institutions try to formulate specific proposals on what has been called "social justice" and mentioned and particularly in a few conversations, generating such diverse attitudes and reactions, in some cases the risk of spending long years of discussions run, Venezuelan educational institutions do not escape it. It is believed faithfully states where education is free as Venezuelan, to fund much of the research since the early years to university undergraduate and provide the ability to hold public office, and make appropriate efforts by its citizens. If not, what remains for those who do not yet have the ability to study, those who have not yet gotten decent work and roam the streets between the pages of a worn and dirty yellow folder both coming and going. However, for human growth, educators, not mere teachers let alone particular party militants are most important and decisive politicians, technicians, engineers or economists. It is as mentioned in various discussions between the teacher and receive education, to match the thought and action, understand, internalize, adapt but being an example and not be in the wrong place, contrary to what is said with what the body does, often with a speech that borders between lie and disappointment believed. ${ }^{2} \mathrm{~A}$ real approach is needed, embody a lifestyle, ideally, Con-born other, thinking about us, 
thinking about school, college, university village. Of the people who get up every day trying to rebuild the social space of their knowledge. But we need to be people identify with him, which smells of earth, suffering, laughing and crying, which has no justification to keep you from walking without blankets. But walking action to teach what a real school and university education need to be linked to the purpose of education in general, in correspondence with the product to be obtained by establishing a model that con-take of the ideal educator profile, reflecting optimal and consistent human being with the need of society. Without forgetting that he is part of society. At the same time, have an academic and philosophical, comprehensive and wellstructured base, which allows up their own ideology. The acquisition of these fundamentals will be in a relevant academic background; not differ from the spontaneous knowledge, ancestral and popular and therefore will be impossible to work in education without acquiring the proper techniques and vocabulary according ... to discern human issues and current problems. Freire ${ }^{3}$ stated:

"...Who is forming, from the very beginning of his experience, also assumed as the subject of knowledge production is definitely convinced that teaching is not transferring knowledge, but to create the possibilities of production or construction? Who teaches learns to teach and who teaches learns to learn. "There is no teaching without discencia (P.26).

The guy every day needs to be educated, trained and instructed de-cognitive holistic way fundamental to life bases, this would reflect a proactive, dynamic and visionary teaching, supported by the acquisition of knowledge to go Reflection to action. But you need to include the workers and not giving gifts of promotions, opportunities and privileges to each other, because it begins exclusion. Let's give the opportunity to enjoy totally free vacation complete with plans, resárcemos their work, let us entrust the task of being better every day but also explain what their role within educational institutions. ${ }^{4,5}$

\section{Results and discussion}

Based on the ideas presented, the current challenge facing the country, Venezuela, our schools, universities, the entire continent is filled with meaning democracy, change antagonistic, selfish, exported "outsight" wrong, exclusive models, "green and red" urban tribes, shortage of exemplary images of losers and annuitants for a productive model and self-production, knowledge generation, free, without passion or fear with any project supported by a rural, environmental, territorial approach , systemic, fighting, belonging and taking responsibility. "It is requested, it seeks...": emotional literacy. It needs that Latin American educational institutions walk, to walk alone. But with us alone. The South. We invent or we err. But recognizing that our interest more than any government position, I repeat, is South America, yes, no ranting or offend the North because they are also Americans. Different but humans nonetheless. Apply diplomacy, not neo- political, relational diplomacy to bridge the gaps and not enlarge.

It is not about returning to Simon Rodriguez or Freire, they already belong to the social imagination of our American history and references are required when the concept of man and education as the common heritage of mankind is mentioned. The timing of the individual, not the collective, or want to make the way we live and feel are the same for everyone, but you need to see with clarity that it is not possible to have uneducated citizens. It seems that the places to provide education became gendarmes, calculators, repetitive, weak, limited, fifteen and last, politicians, parasites and others, without thinking that the product is released to the streets carrying the germ of our pollution. They fail to fill the spirit. These "non-places" work, in most cases with "guidelines" managers briefcase, "people who sold their comfort, their thinking, their freedom, their way of being and autonomy: focus on absenteeism and presenteeism, which attends a school, a high school or university because his image adorns entries unions, programs, profiles, schedule and supervision, communal work. Of course, it is the iron lady or man of steel. Result: discouragement, despair, desertion swarming in our classrooms, sadness, too much poverty and violence that now owns the streets, jumped railings schools, walking the corridors of universities and done in cemeteries.

\section{Conclusion}

It could be a utopia, free institutions educational quality centers where you live and life, where outbreak innocence and youth build, sexuality and respect, where community is built, the other party, it is up to parents, home and family. And as trainers, who have the scope to be, help rescue. Educational institutions, without excluding any, should be places of integrated production, expression and celebration of life, daily spaces for training, retention and participation of citizens, intellectual production, extension and true teaching. If they are so irrelevant, traditional, tedious and boring educational institutions, we use the house-classroom provoke family integration. Transform schools, at a time when prevailing culture of death and most students experience life as insecurity, fear, violence, frustration, loneliness and anomie. Educational institutions, without leaving any side should be places where people live and allows com-union of knowledge, provided they can observe the true dimensions of education and begin to crumble the walls of individual blindness; where the real task is no longer more in classrooms and from the classroom but in the hearts of the people and for the people that represents the essence of a true educational proposal. It is a chimera. Consequently, it attempts from our position as educators, based on opinions and skeletal and weak as opposed to examine arguments, as well as educators, reasoned explication of shared knowledge but grounded in the study and reflection. Aspects that could be taken into account for the differences in concepts underlying this article and not by political differences that sometimes glimpse in his words. It was not our intention. Educational institutions belong to the people; they are collective property. It would be bad if the words and thoughts were directed on those who today hold the official authority in all government charges the Spanish American continent because we would, on universities and on the earth beneath our feet. That is a responsibility of each. Sooner or later the rivers overflow where the lower the rate. Everything depends on us. Aspects that could be taken into account for the differences in concepts underlying this article and not by political differences that sometimes glimpse in his words. It was not our intention. Educational institutions belong to the people; they are collective property. It would be bad if the words and thoughts were directed on those who today hold the official authority in all government charges the Spanish American continent because we would, on universities and on the earth beneath our feet. That is a responsibility of each. Sooner or later the rivers overflow where the lower the rate. Everything depends on us. Aspects that could be taken into account for the differences in concepts underlying this article and not by political differences that sometimes glimpse in his words. It was not our intention. Educational institutions belong to the people; they are collective property. It would be bad if the words and thoughts were directed on those who today hold the official authority in all government charges the Spanish American continent because we would, on universities and on the 
earth beneath our feet. That is a responsibility of each. Sooner or later the rivers overflow where the lower the rate. Everything depends on us. It was not our intention. Educational institutions belong to the people; they are collective property. It would be bad if the words and thoughts were directed on those who today hold the official authority in all government charges the Spanish American continent because we would, on universities and on the earth beneath our feet. That is a responsibility of each. Sooner or later the rivers overflow where the lower the rate. Everything depends on us. It was not our intention. Educational institutions belong to the people; they are collective property. It would be bad if the words and thoughts were directed on those who today hold the official authority in all governs.

\section{Acknowledgments}

None.

\section{Conflicts of interest}

Author declares that there is none of the conflicts.

\section{References}

1. Cohn J. Pedagogía fundamental. Revista de Pedagogía. 1933.

2. Fourez G. La Construcción del conocimiento científico- filosófico y ética de la ciencia. 1994.

3. Freire P. Pedagogy of autonomy. Mexico. In: Delors J, editor. 1966.

4. Esclarín A. Parents: First and foremost educators of their children. Venezuela: San Pablo trials. Caracas; 2011

5. Bathrobe A. University Reform or experiment. Venezuela: Ieselac-Unesc; 2013. 